\title{
АКТУАЛЬНЫЕ КОНСТИТУЦИОННО-ПРАВОВЫЕ ПРОБЛЕМЫ РУКОВОДСТВА ФЕДЕРАЛЬНЫМИ ОРГАНАМИ ИСПОЛНИТЕЛЬНОЙ ВЛАСТИ
}

\author{
О. А. Ибрагимов \\ Акаделия управления МВД России \\ Поступила в редакцию 15 января 2021 г.
}

\begin{abstract}
Аннотация: расслатриваются проблелы принятия и реализации управленческих решений Правительствол РФ. Особое внилание акиентировано на проблемах организаиии руководства главой правительства и его заместителяли, а также органами исполнительной власти, находящилися в ведении Президента РФ. Предлагается ряд конституиионно-правовых мер совершенствования организации принятия управленческих решений, заключающихся в точечной корректировке управленческих взаилодействий. Ключевые слова: исполнительная власть, феедеральное правительство, управление, президент, коллегиальность.
\end{abstract}

\begin{abstract}
: the article deals with the problems of making and implementing administration decisions by the Government of the Russian Federation functioning under the general direction of the main official of the state. Author's special attention is focused on the problems of organizing the administration of the head of government and his deputies, as well as the administration of executive bodies under the jurisdiction of the Russian Federation President. The author proposes a number of constitutional measures to improve the organization of administration decision-making, which consists of the point adjustment of administration interactions.
\end{abstract}

Key words: executive power, federal government, administration, president, collegiality.

В Российской Федерации исполнительная власть занимает центральное место в системе разделения властей. Исполнительная власть организует жизнь практически каждого гражданина, выполняя огромное число распорядительных функций. Реализация органами исполнительной власти государственно-властных фонкций влияет как на права и свободы отдельного человека, так и на интересы общества в целом.

Исполнительная власть неразрывно связана с государственным управлением. Она представляет собой один из институтов государственного управления и реализует функцию управления. Исполнительной власти необходимо постоянно адаптироваться к потребностям государственного управления, основное бремя которого возложено на нее ${ }^{1}$. Meханизм государственного управления непосредственно реализуется посредством фрункционирования исполнительной власти, воздействуя на

${ }^{1}$ См.: Исполнительная власть в Российской Федерации. Проблемы развития / отв. ред. И. Л. Бачило. М., 1998. С. 72.

(с) Ибрагимов О. А., 2021 


\section{Вестник ВГУ. Серия: Право}

различные сферы общественных отношений в целях обеспечения эффективной жизнедеятельности общества ${ }^{2}$. Анализу функции государственного управления исполнительной власти посвящено множество исследований по конституционному праву, но ввиду поступательного и динамического развития этой ветви власти существует необходимость периодического осмысления направлений ее преобразований.

В Советском государстве исполнительная власть фрактически отождествлялась с аппаратом государственного управления ${ }^{3}$, но по итогам преобразования государственной системы в начале 1990-х гг. произошел постепенный отказ от использования термина «государственное управление» в законодательстве, а впоследствии и в научной литературе. В современной России существующая система государственного управления значительно шире исполнительной власти, поэтому и предлагается ее определять как целостную сферу деятельности государственной власти, всех ее ветвей, органов и должностных лиц ${ }^{4}$. Функции исполнительной власти (равно как и задачи, полномочия, основные направления) и собственно Правительства РФ производны от государственного управления $^{5}$. Положениями новой редакции 2020 г. Основного закона ${ }^{6}$ регламентировано, что исполнительная власть входит в единую систему публичной власти, поэтому, вероятнее всего, в контексте деятельности органов государственной власти понятие «государственное управление» со временем трансформируется в понятие «публичное управление».

Руководствуясь положениями концепции М. Вебера о «рациональной бюрократии», следует признать, что одним из существенных отличий публичного управления (в современной рациональной демократии) от государственного (в традиционной «патримониальной» демократии) является применение подходов в управлении, характерных для част-

$\sim$ нохозяйственной деятельности ${ }^{7}$. Современные теории государственного

일 управления (новый государственный менеджмент, концепция управления "governance», теория хорошего управления) исходят также из необходимости применения рыночно-ориентированных методов управления, партнерства государства и частного сектора, социальной эффеективности ${ }^{8}$.

$90{ }^{2}$ См.: Правительство Российской Федерации / под ред. Т. Я. Хабриевой. М., 2005. C. 108.

${ }^{3}$ См.: Лазарев Б. М. Аппарат управления общенародного государства. М., 1978. C. 3.

${ }^{4}$ См.: Чиркин В. E. Публичное управление. М., 2004. С. 98.

${ }^{5}$ См.: Правительство Российской Федерации / под ред. Т. Я. Хабриевой. С. 110.

${ }^{6}$ Конституция Российской Федерации : принята всенародным голосованием 12 декабря 1993 г. с изм., одобренными в ходе общероссийского голосования 1 июля 2020 г. // Официальный интернет-портал правовой информации. URL: http://publication.pravo.gov.ru/Document/View/0001202007040001

${ }^{7}$ См.: Масловский М. В. Теория бюрократии Макса Вебера и современная политическая социология. Н. Новгород, 1997. С. 37.

${ }^{8}$ См.: Правовое обеспечение государственного управления и исполнительная власть : учеб. для магистров / под ред. С. А. Старостина. М., 2020. С. 30-33. 
Если в советское время актуальные рыночно- и социально ориентированные подходы к организации государственного управления были преданы забвенью, то в настоящее время применение их методов в организации управления органами исполнительной власти открывает широкие возможности для социально-экономического развития России. Публичное управление не отрицает рациональное использование административных методов государственного управления, и от эффективности их применения зависит организация исполнительной власти в современной России, только начинающей свой путь к выстраиванию истинно демократической и социальной системы публичной власти.

Многие ученые-конституционалисты предельно теоретизируют изучение проблем реализации фрункций исполнительной власти, абстрагируясь от анализа их практических составляющих: например, организации руководства должностными лицами, обладающими конституционными полномочиями и занимающими государственные должности, такими как Президент РФ и члены Правительства РФ. Российская конституционно-правовая модель центрального правительства предполагает включение ограниченного круга должностных лиц - членов правительства, которые формируют его персональный состав. На практике каждый член Правительства РФ призван в рамках своих полномочий обеспечить реализацию принципов единоначалия по отношению к подчиненному объекту управления и коллегиальности правительства в целом. Де-юре организация руководства членами правительства регламентируется их правовым положением, но де-фракто в процессе его осуществления принятие управленческих решений обусловлено влиянием различных фракторов: политических, личностных, экономических, социальных и т. д. В связи с этим необходимо обратить пристальное внимание на проблемы организации управления фредеральным правительством, а также руководства его членами.

В научных работах отмечается дуалистическая форма организации исполнительной власти на федеральном уровне ${ }^{9}$, так как в руководстве принимают участие не только члены Правительства РФ, но и высшее должностное лицо государства и иные руководители федеральных органов исполнительной власти. Важнейшую роль в организации эфрективного управления играет решение конституционно-правовых проблем взаимоотношений Президента РФ с системой органов исполнительной власти, которые до сих пор порождают различные дискуссии в научном сообществе, активно возрастающие в свете последних изменений в Конституции РФ.

В 2020 г. произошло изменение конституционного статуса фредерального правительства. Согласно положениям нового закона о Правитель-

${ }^{9}$ Например, см.: Авдееев Д. А. Форма правления в России (краткий конституционный очерк). Тюмень, 2015. С. 132 ; Чесноков А. С. Исполнительная власть в Российской Федерации : теоретико-правовой анализ : дис. ... канд. юрид. наук. М., 2001. C. 65. 


\section{Вестник ВГУ. Серия: Право}

стве $Р \Phi^{10}$, оно является органом публичной власти, одним из компонентов системы исполнительной власти наряду с иными ее органами на федеральном и региональном уровнях. В соответствии с положением ст. 1 ранее действовавшего законодательного акта ${ }^{11}$ Правительство РФ являлось высшим органом исполнительной власти в Российской Федерации, что, по мнению С. А. Авакьяна, определяло его первое место в иерархии органов исполнительной власти ${ }^{12}$. «Законодательная реконструкция» конституционного статуса федерального правительства, на первый взгляд, не имеет существенного значения, но соотнесение его нового положения с внесенными в ст. 83 и 110 Конституции РФ изменениями, касающимися осуществления Президентом РФ общего руководства федеральным правительством, дает право актуализировать научные взгляды об условности его высшего положения и несамостоятельности своей деятельности ${ }^{13}$. Основной закон соответствующими изменениями укрепил позиции Президента РФ как ключевой фигуры в системе управления правительством, но в то же время не изменил его обособленное положение по отношению к исполнительной власти. Таким образом, право организации руководства правительством официально закреплено за высшим должностным лицом государства и при этом нивелируется высшее положение Правительства РФ в системе исполнительной власти. Впоследствии это может привести к снижению качества принятия коллегиальных решений федеральным правительством, а в крайнем случае - к утрате самостоятельности и фактической зависимости от Президента РФ.

Основной закон наделяет конституционно-правовыми полномочиями как сам орган управления - Правительство РФ, так должностных лиц, входящих в его состав. Правительство РФ руководит деятельностью федеральных органов исполнительной власти (ч. 3 ст. 110 Конституции РФ), а

$\sim$ именно федеральными министерствами и иными федеральными органа이 ми исполнительной власти (ст. 12 закона о Правительстве РФ). Но сам по себе орган власти «руководить» не может, реальный процесс руководства всегда связан с правами и обязанностями должностных лиц, входящих в его состав. Понятие "руководство», исходя из словарных его толкований, заключается в направлении деятельности, управлении чем-либо, ведении по какому-нибудь пути и т. д. ${ }^{14}$, по смыслу тождественно понятию

${ }^{10} \mathrm{O}$ Правительстве Российской Федерации : федер. конституц. закон от 6 октября 2020 г. № 4-ФКЗ // Официальный интернет-портал правовой информации. URL: http://publication.pravo.gov.ru/Document/View/0001202011060001?index=1\&r angeSize $=1$

${ }^{11} \mathrm{O}$ Правительстве Российской Федерации : федер. конституц. закон от 17 декабря 1997 г. № 2-ФКЗ // Собр. законодательства Рос. Федерации. 1997. № 51. Ст. 5712.

${ }^{12}$ См.: Организация государственной власти в России и зарубежных странах : учеб.-метод. комплекс / отв. ред. С. А. Авакьян. М., 2014. С. 58.

${ }^{13}$ См.: Баглай M. В. Конституционное право Российской Федерации : учеб. для вузов. М., 2000. С. 154.

14 Электронная база словарей. URL: https:/gufo.me/dict/ozhegov/руководить 
«управление». По мнению автора, конституционно-правовые нормы, содержащие понятия «руководство», «управление» по отношению к органам власти не отражают правовой реальности и заключают в себе неопределенное значение, поэтому требуют юридической корректировки. По отношению к Правительству РФ наиболее успешно выглядит конструкция «принятие управленческих решений», чем понятие «управление».

Предположим, что конституционное полномочие Правительства РФ по руководству деятельностью органами власти связано с принципом его коллегиальности, основанном на непосредственном участии его членов в принятии управленческих решений. Коллегиальное принятие управленческих решений производится, как правило, на заседаниях Правительства РФ, при участии не менее половины его членов, общим согласием или путем голосования большинством голосов ${ }^{15}$. В первом случае принятие управленческих решений общим согласием, т. е. единогласным решением, негативно отражается на плюрализме мнений и исключает открытые несогласия членов правительства с мнением большинства. В другом случае при использовании процедуры голосования минимальное число голосов для принятия решения может быть несколько выше 25 процентов, что будет иметь отрицательное влияние на качество принимаемого решения. Решить указанные проблемы предлагается путем значительного увеличения количественного порога заседания Правительства РФ до $2 / 3$ его членов, а также при голосовании решение считать принятым при поддержке его более $2 / 3$ голосов. Считаем необходимым согласиться с мнением А. В. Нечкина об использовании тайного голосования на заседаниях правительства ${ }^{16}$.

Как известно, Правительство РФ и его члены наделены различными конституционными полномочиями, многие из которых неразрывно связаны с организацией управления. В связи с этим видится необходимость инкорпорирования правовой нормы ч. 3 ст. 110 Конституции РФ о руководстве деятельностью федеральными органами исполнительной власти в отношении Председателя Правительства РФ, его заместителей и федеральных министров в ст. 27-29 закона о Правительстве РФ, исходя из компетенции должностного лица. Например, дополнением полномочий Председателя Правительства РФ могла бы стать правовая норма об обязанности руководства (или управления) деятельностью фредеральными органами исполнительной власти, заместителями Председателя Правительства РФ и федеральными министрами. Конституционно-правовые нормы, касающиеся наделения главы центрального органа исполнительной власти полномочиями по руководству этим органом, регламен-

${ }^{15}$ О Регламенте Правительства Российской Федерации и Положении об Аппарате Правительства Российской Федерации : постановление Правительства РФ от 1 июня 2004 г. № 260 (в ред. от 10.10.2020) // Собр. законодательства Рос. Федерации. 2004. № 23. Ст. 2313.

${ }^{16}$ См.: Нечкин A. B. Коллегиальность в работе правительства на примере Российской Федерации и других стран Содружества Независимых Государств // Конституционное и муниципальное право. 2016. № 5. С. 23-24. 
тированы конституциями Австрии (ст. 77), Армении (ст. 87), Беларуси (ст. 106), Болгарии (ст. 108), Испании (ст. 98), Казахстана (ст. 67), Польши (ст. 148), Румынии (ст. 106), Франции (ст. 21) и др. Аналогичная конституционно-правовая норма актуальна и для других членов федерального правительства России, исходя из их компетенции, и в настоящее время установлена конституциями Австрии (ст. 77), Болгарии (ст. 108), Германии (ст. 65), Польши (ст. 149) и др.

Институт заместителей председателей глав центральных правительств - нечастое явление в конституционном праве зарубежных государств. В России конституционно-правовое регулирование организации руководства заместителями Председателя Правительства РФ основано на координации работы федеральных органов исполнительной власти (в соответствии с распределением обязанностей) и даче им поручений. Общее понятие «координация» заключается во взаимосвязи, согласовании, приведении в соответствие ${ }^{17}$. Одним из вариантов узкого значения понятия «координация» является его представление как части функции управления, «осуществляемой по отношению к организационно подчиненным объектам управления, не затрагивающей их оперативной самостоятельности» ${ }^{18}$. Законодателем не определены конкретные формы координации, что при принятии важных управленческих решений может привести к нарушению конституционно-правового принципа коллегиальности Правительства РФ и неравенству положений федеральных министерств. На практике заместитель Председателя Правительства РФ в пределах своей компетенции не только координирует деятельность федеральных министров и органов власти посредством методического руководства, участия в нормативном регулировании, применения мер разрешительного характера, законодательной инициативы и т. д., но и

$\sim$ выполняет часть полномочий, делегированных ему президентом и гла을 вой правительства. Реализация указанных полномочий значительно шире деятельности по координации работы федеральных органов исполнительной власти. В связи с этим существует необходимость закрепления в законе о Правительстве РФ нормы права о порядке реализации и разграничения полномочий, делегированных заместителю Председателя Правительства РФ президентом и главой правительства.

Правовое положение заместителей Председателя Правительства РФ в области конституционно-правовой ответственности за принятие управленческих решений в связи с изменениями Основного закона в 2020 г. значительно преобразовалось. С одной стороны, конституционно-правовая норма об их подотчетности Президенту РФ и Председателю Правительства РФ призвана повысить уровень ответственности за принятие решений при осуществлении полномочий (ч. 2 ст. 28 федерального кон-

17 Электронная база словарей. URL: https:/gufo.me/dict/bes/координация

18 Галимова A. Г. Место Правительства РФ в системе исполнительной власти // Вестник Восточно-Сибирского института Министерства внутренних дел России. 2009. № 3 (50). С. 42. 
ституционного закона о Правительстве). В то же время указанная норма права подкрепляет их "неоднозначное» правовое положение, так как фактически руководство их деятельностью осуществляет глава государства и правительства. Президент РФ, помимо поручений, может возлагать на них выполнение конкретных задач в области руководства органами исполнительной власти «силового блока» - федеральными органами исполнительной власти, находящимися в его ведении ${ }^{19}$. У Председателя Правительства РФ такое право отсутствует. Правовое значение президентских поручений важнее аналогичных главы Правительства РФ, поэтому его заместитель может принимать управленческие решения независимо от руководителя правительства в определенной степени. Возникает проблема подотчетности реализации конкретного полномочия заместителя Председателя Правительства РФ, решение этой проблемы видится в уточнении анализируемой конституционно-правовой нормы.

Президент РФ как высшее должностное лицо государства обладает реальными властными полномочиями над исполнительной властью в целом и над фредеральным правительством в частности. Об этом свидетельствуют, по меньшей мере, три конституционные правовые нормы. Во-первых, согласно ч. 2 и 3 ст. 80 Президент РФ обеспечивает согласованное функционирование и взаимодействие органов, входящих в единую систему органов власти, а также определяет основные направления внутренней и внешней политики государства. Указанные конституционные положения на практике реализуются в виде участия Президента РФ в осуществлении исполнительной власти ${ }^{20}$, иными словами - в руководстве органами исполнительной власти. Во-вторых, правовые нормы ст. 115 Конституции РФ обязывают Правительство РФ осуществлять правотворческую деятельность на основании указов, распоряжений и поручений Президента РФ. В-третьих, это полномочие по осуществлению общего руководства Правительством РФ. Законодателем не раскрывается понятие «общее руководство», но по смыслу оно тождественно понятию «общее управление». Конституционно-правовая норма по осуществлению общего руководства Президентом РФ в целом определяет его исключительную роль в руководстве федеральным правительством как органом власти. С точки зрения положений Основного закона Президент РФ не входит в структуру федерального правительства, но имеет право руководить им, что фактически ставит Правительство РФ в положение подчиненности высшему должностному лицу государства. Это, как уже было отмечено, снижает уровень независимости исполнительной власти в принятии управленческих решений в пределах своей компетенции. Такое положение при определенных политических кризисах может стать одним из рисков перехода России к авторитарному режиму правления.

${ }^{19}$ Правительство Российской Федерации / под ред. Т. Я. Хабриевой. С. 151.

${ }^{20}$ См.: Ибрагилова Н. Ш. Президент и Правительство в системе исполнительной власти Российской Федерации // Вестник Северо-Кавказского гос. техн. ун-та. 2006. № 5 (9). С. 106. 
Президент РФ осуществляет не только общее руководство деятельностью Правительства РФ, но и руководит деятельностью федеральных органов исполнительной власти «силового блока», в связи с чем в научном сообществе до сих пор дискутируют о проблеме «двойного подчинения» этих органов ${ }^{21}$. Определяющим аргументом дискуссии является конституционно-правовая норма о фактически единоличном полномочии Президента РФ по назначению на должности и освобождению от нее руководителей (п. «д ${ }^{1}$ ст. 83 Основного закона). Консультации Президента РФ с Советом Федерации при назначении на должности руководителей федеральных органов исполнительной власти «силового блока» имеют рекомендательное значение и не могут повлиять на конституционный выбор главой государства конкретной кандидатуры. В ч. 4 ст. 12 закона о Правительстве РФ определены полномочия Президента РФ по непосредственному руководству указанными органами или через назначаемых им федеральных министров. Правительство РФ в соответствии с нормативными актами Президента РФ координирует их деятельность, но законодательным актом не определены формы координации, неясны и пределы ее осуществления. В связи с этим принцип коллегиальности деятельности федерального правительства не может быть реализован в полной мере, так как на принятие управленческих решений членами правительства «силового блока» оказывает влияние Президент РФ, их непосредственный руководитель. По мнению В. В. Гончарова, такое положение органов власти «силового блока» может привести к «конфоликтным ситуациям в части определения приоритета руководящих указаний обоих центров управления системой исполнительной власти» ${ }^{22}$. Заместители Председателя Правительства РФ также де-юре выключены из процесса взаимодействия с органами власти «силового блока», что может $\sim$ стать препятствием по осуществлению ими в полной мере полномочий 은 по координации работы федеральных органов исполнительной власти. Итак, единоличное руководство органами власти «силового блока» приводит к определенным нарушениям принципа единоначалия федерального правительства, в связи с чем его глава не может полноценно управлять им как целостной системой.

96 Таким образом, конституционно-правовое обеспечение руководства федеральными органами исполнительной власти нуждается в корректировке управленческих взаимосвязей и уточнении некоторых юридических понятий. Целесообразно максимизировать привлечение членов Правительства РФ к участию в коллегиальных мероприятиях для повышения качества и прозрачности стратегических решений. По итогам умозаключения, касающихся гипотезы о тесной взаимосвязи управлен-

${ }^{21}$ См.: Осетров С. А. Организационные основы президентской власти в Российской Федерации // Конституционное и муниципальное право. 2010. № 7. С. 42.

${ }^{22}$ Гончаров В. В. Коллегиальность и единоначалие как принципы формирования и функционирования органов исполнительной власти в РФ // Юрид. мир. 2009. № 3 (147). C. 56. 
ческой функции федерального правительства с принципом его коллегиальности, предлагается конституционализировать конструкцию «принятие управленческих решений» вместо «управление».

Исходя из высокой значимости организации механизма управления в органах исполнительной власти одним из дополнений конституционных правовых норм могли бы стать положения закона о Правительстве РФ, регламентирующие обязанность руководства (или управления) деятельностью подчиненными органами власти главой Правительства РФ и федеральными министрами в пределах своей компетенции. В связи с дихотомическим характером руководства заместителями Председателя Правительства РФ существует необходимость уточнения порядка реализации ими полномочий. Конституционно-правовая норма, регламентирующая полномочие Президента РФ по общему руководству феддеральным правительством, может привести к снижению уровня его самостоятельности в принятии коллегиальных решений. Право единоличного управления органами власти «силового блока» Президентом РФ, по мнению автора, нарушает принципы единоначалия и коллегиальности федерального правительства.

Обсуждение и осмысление точечных и системных проблем организации управления в органах исполнительной власти, в том числе в феeдеральном правительстве, необходимо для повышения эфрфективности принятия управленческих решений. В свою очередь, верно принятое управленческое решение - залог его успешной реализации в будущем.

\section{Библиографический список}

Авдееев Д. А. Форма правления в России (краткий конституционный очерк). Тюмень, 2015. 244 с.

Баглай $M$. В. Конституционное право Российской Федерации : учеб. для вузов. М., 2000. 760 с.

Галилова А. Г. Место Правительства РФ в системе исполнительной власти // Вестник Восточно-Сибирского ин-та Министерства внутренних дел России. 2009. № 3 (50). С. 38-45.

Гончаров В. В. Коллегиальность и единоначалие как принципы формирования и функционирования органов исполнительной власти в РФ // Юридический мир. 2009. № 3 (147). С. 54-58.

Ибрагилова Н. Ш. Президент и Правительство в системе исполнительной власти Российской Федерации // Вестник Северо-Кавказского гос. техн. ун-та. 2006. № 5 (9). С. 105-107.

Исполнительная власть в Российской Федерации. Проблемы развития / отв. ред. И. Л. Бачило. М., 1998. 432 с.

Лазарев Б. М. Аппарат управления общенародного государства. М., 1978. $88 \mathrm{c}$.

Масловский M. В. Теория бюрократии Макса Вебера и современная политическая социология. Н. Новгород, 1997. 88 с.

Нечкин A. B. Коллегиальность в работе правительства на примере Российской Федерации и других стран Содружества Независимых Государств // Конституционное и муниципальное право. 2016. № 5. С. 22-25. 
Организация государственной власти в России и зарубежных странах : учеб.-метод. комплекс / отв. ред. С. А. Авакьян. М., 2014. 692 с.

Осетров С. А. Организационные основы президентской власти в Российской Федерации // Конституционное и муниципальное право. 2010. № 7. C. $41-44$.

Правительство Российской Федерации / под ред. Т. Я. Хабриевой. М., 2005. 608 c.

Правовое обеспечение государственного управления и исполнительная власть : учеб. для магистров / под ред. С. А. Старостина. М., 2020. 336 с.

Чесноков A. C. Исполнительная власть в Российской Федерации : теоретико-правовой анализ : дис. ... канд. юрид. наук. М., 2001.

Чиркин В. E. Публичное управление. М., 2004. 475 с.

Электронная база словарей. URL: https://gufo.me/dict/bes/координация.

Электронная база словарей. URL: https://gufo.me/dict/ozhegov/руководить.

\section{References}

Avdeev D. A. Form of government in Russia (brief constitutional sketch): monograph. Tyumen, 2015. $244 \mathrm{p}$.

Baglay M. V. Constitutional law of the Russian Federation : textbook for universities. M., 2000. 760 p.

Galimova A. G. The place of the Russian Federation Government in the system of executive power // Bulletin of the East Siberian Institute of the Ministry of the Interior of Russia. 2009. No. 3 (50). P. 38-45.

Goncharov $V . V$. Collegiality and unity of command as principles of formation and functioning of executive authorities in the Russian Federation / / Legal World. 2009. No. 3 (147). P. 54-58.

Ibragimova N. Sh. President and Government in the system of executive power of the Russian Federation / / Vestnik Severo-Kavkazskogo gosudarstvennogo tekhnicheskogo universiteta. 2006. No. 5 (9). P. 105-107.

일 Executive power in the Russian Federation. Problems of development / Ed. I. L. Bachilo. M., 1998. 432 p.

Lazarev B. M. Apparatus of management of the national state. M., 1978. $88 \mathrm{p}$.

Maslovsky M. V. Max Weber's theory of bureaucracy and modern political sociology. N. Novgorod, 1997. $88 \mathrm{p}$.

Nechkin A. V. Collegiality in the work of the government on the example of the Russian Federation and other countries of the Commonwealth of Independent States / / Constitutional and municipal Law. 2016. No. 5. P. 22-25.

Organization of state power in Russia and foreign countries. Educational and methodical complex / Ed. S. A. Avakian. M., 2014. 692 p.

Osetrov S. A. Organizational foundations of presidential power in the Russian Federation / / Constitutional and municipal law. 2010. No. 7. P. 41-44.

Government of the Russian Federation / Edited by T.Ya. Khabrieva. M., 2005. 608 p.

Legal support of public administration and executive power : textbook for masters / Ed. by S.A. Starostin. M., 2020. 336 p. 
Chesnokov A. S. Executive power in the Russian Federation : Theoretical and legal analysis: dis. cand. of law sciences. M., 2001.

Chirkin V. E. Public administration. M., 2004. 475 p.

Electronic database of dictionaries. URL: https://gufo.me/dict/bes/координация.

Electronic database of dictionaries. URL: https:/gufo.me/dict/ozhegov/руководить.

Акаделия управления МВД России

Ибрагимов О. А., адъюнкт

E-mail:464941@rambler.ru
Academy of the Russian Ministry of Internal Affairs

Ibragimov O. A., Adjunct

E-mail: 464941@rambler.ru 